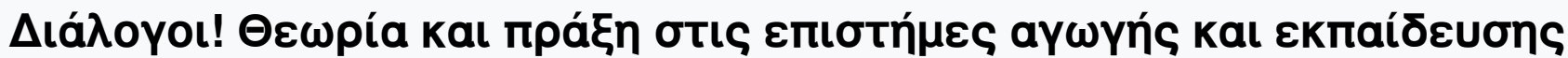

Tó 2 (2016)

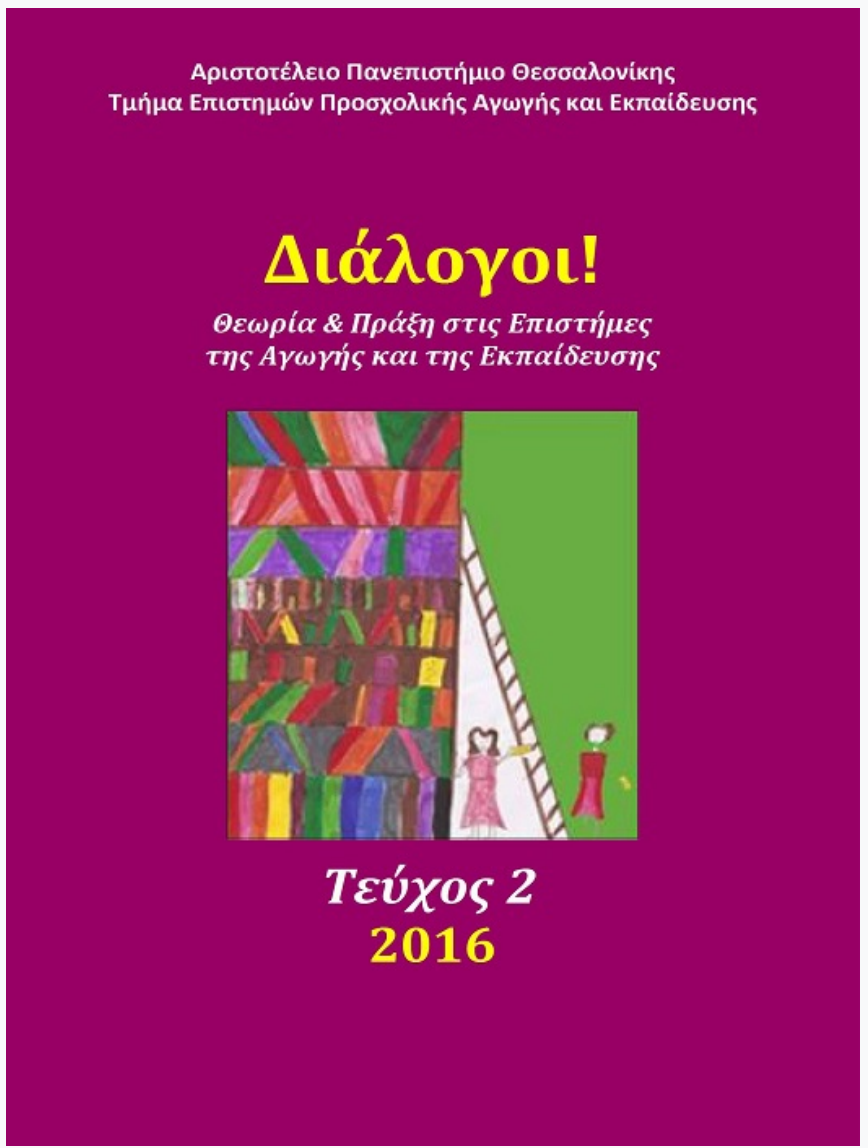

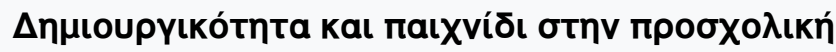

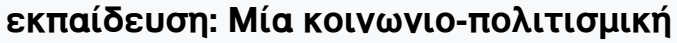

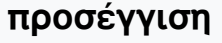

Sofia Avgitidou

doi: $\underline{10.12681 / \text { dial.10570 }}$

Copyright @ 2016, Sofia Avgitidou

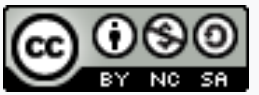

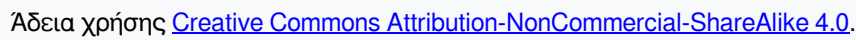

\section{Bıß入ıорачıкń avaчopá:}

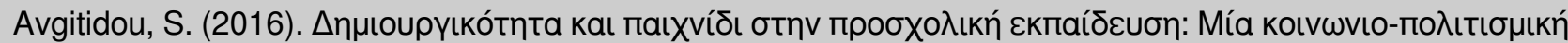

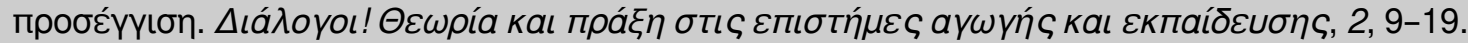

https://doi.org/10.12681/dial.10570 


\title{
Creativity and play in early childhood education: a socio-cultural perspective
}

\author{
Sofia Avgitidou \\ University of Western Macedonia
}

\begin{abstract}
Creativity has mostly been associated with a cognitive capacity linked with specific qualities of thought such as the production of new ideas, originality, imagination and flexibility during problem solving. This study highlights creativity within a socio-cultural theoretical perspective as displayed during children's free play in early childhood settings. By employing a socio-cultural perspective, this paper questions: a) the ways in which children may be creative during free-play activities and b) the ways in which teachers' values, organization of educational practice and classroom rules intervene in the opportunities and ways in which children express creativity during play. Ethnographic observations and interviews with the children and early childhood teachers took place in two early childhood settings, characterized by different teachers' priorities, time and space organization of free play. Creativity and play are linked by identifying children's meaningful and intended interactions to change the context of play (time, space, rules, scenaria) through either the adaptation of adult values and concerns or the construction of new meanings, forms and activities that add to the existing culture. The paper concludes with tentative proposals for teachers on how to recognize the potential of children's creativity within play and support related opportunities.
\end{abstract}

Keywords: play, creativity, early childhood education

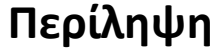

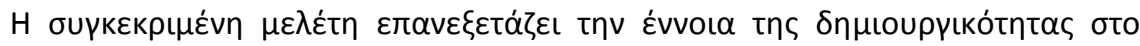

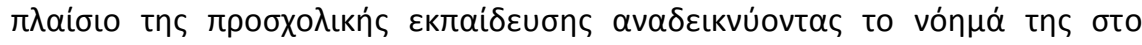

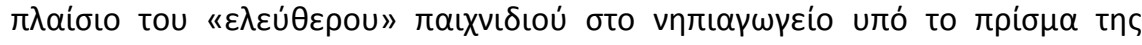

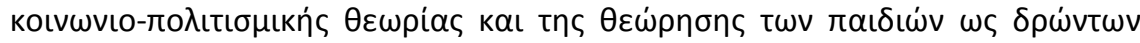

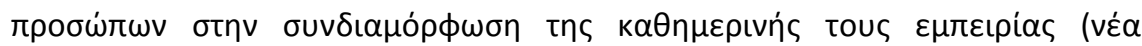

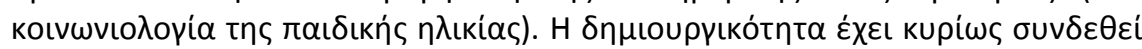

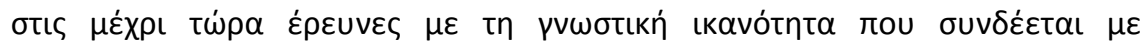

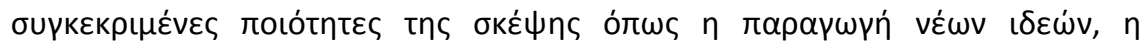

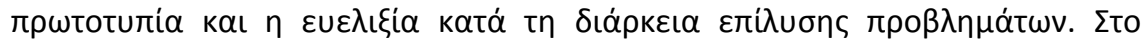

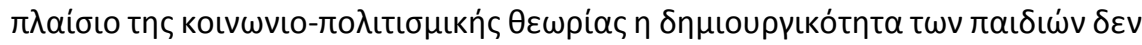

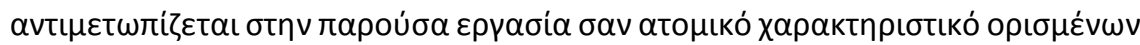

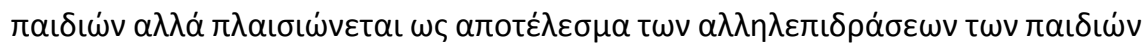

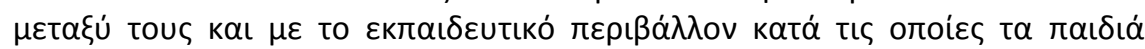

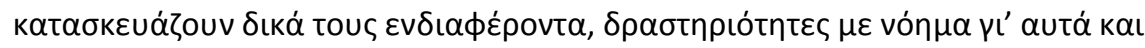

Correspondent author: Sofia Avgitidou, Professor, Department of Early Childhood, Faculty of Education, University of Western Macedonia, e-mail: saugitidoy@uowm.gr 


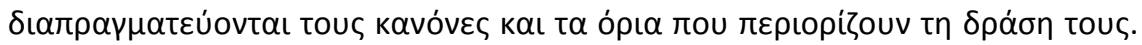

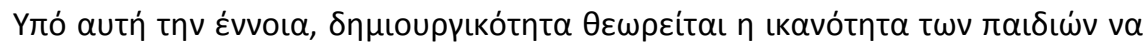

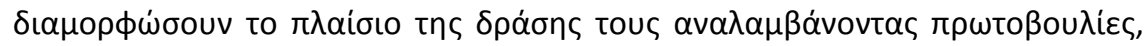

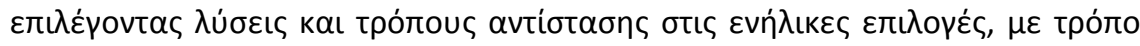

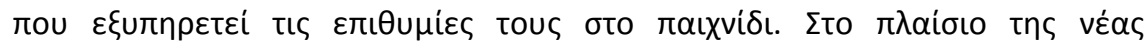

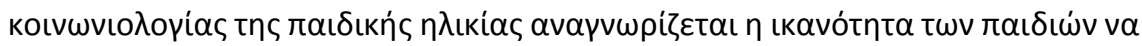

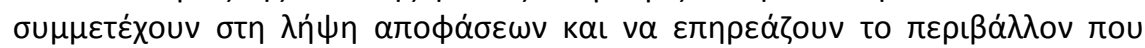

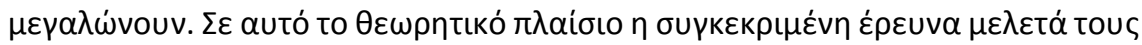

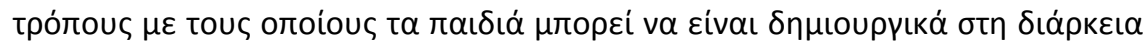

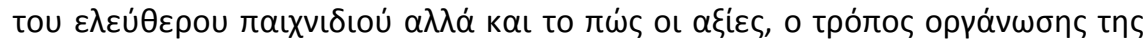

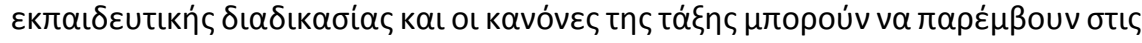

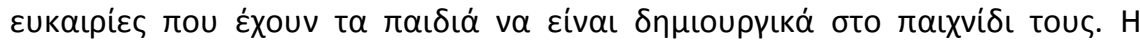

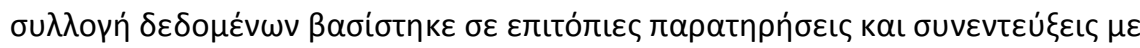

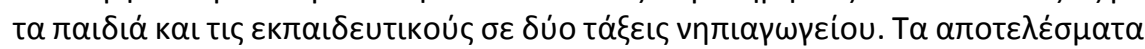

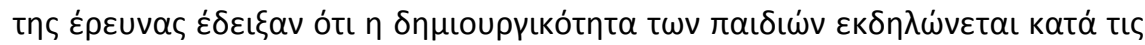

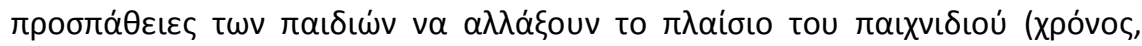

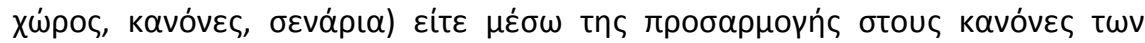

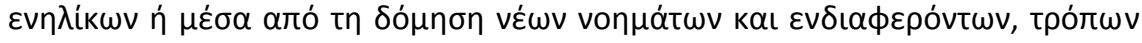

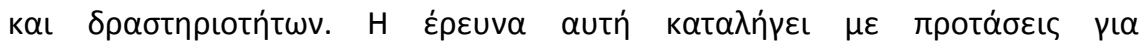

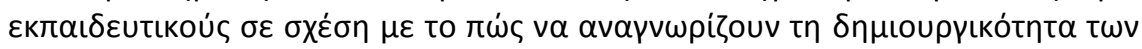

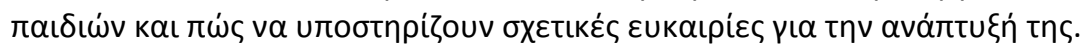

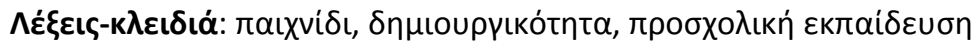

\section{Introduction}

The aim of this paper is to promote an understanding of creativity as a sociocultural everyday process (and not only as a psychological, individual process) in the context of children's play in early childhood education. It also aims to highlight both children's agency as well as the importance of this agency for children's learning to be part of and contribute to the social world they live in. Within the context of the current special issue titled "Children's play in a changing world", this paper discusses the position of play in relation to the changing discourse observed in early childhood education that seeks for measured outcomes and standardization of learning processes. Furthermore, it depicts play as a socio-cultural activity within which children are active agents in forming their peer and school culture(s).

Play is an important aspect of early childhood education (ECE) curriculum in Greece and an official part of the daily program of the kindergarten. However, practitioners may vary in their reasoning of the value of play and their related practices since they transform the curriculum in their classrooms according to their personal theories about ECE priorities, childhood and their role as teachers (Loizou \& Avgitidou, 2014). Researching play in early childhood education calls upon the need to explore it in relation to context and specifically in relation to differentiated practitioners' beliefs and practices. Thus, the different theoretical assumptions underlying different practices regarding play in ECE are recognized to have different underlying consequences in positioning children and practitioners in ECE.

We know that different theoretical paradigms (psychoanalysis, developmental psychology, socio-cultural theory, childhood studies and other) have provided different 
understandings of the value of play (Avgitidou, 2001). During the last years, we can see two trends regarding the role of play in early childhood education. The first trend relates the value of play to learning outcomes, leading to an instrumentalisation and regulation of play (Moss, 2007) that legitimizes play because of its relation to concrete learning. The trend for a standardization of ECEC has effects on play even in countries such as the Nordic ones that have a tradition of a child-centred, holistic approach with an emphasis on participation, democracy, autonomy and freedom (Karila, 2012). The second trend relates the arguments for the value of play to an appreciation of childhood experience in the here and now sphere and the recognition of children's contribution as citizens in the world they live in, through their participation in meaningful and collective activities, such as play (Avgitidou, 2001; Corsaro, 1985; Tsigra, 2014). The relationship between play and neoliberal trends that stress the value of knowledge, skills acquisition and the need for accountability in education has also been emphasized by recent publications regarding play (Hännikainen, Singer, \& van Oers, 2013, p. 165). Accordingly, the relationship between play and children's creativity may take different meanings in the context of the trends described above.

Emphasis so far has been given to creativity as an individual, psychological process presented in all theories, usually related to imagination, innovation and adaptability (Saracho, 2010, p. 5) and creativity as related to curriculum subjects (arts, mathematics, language). These approaches do not give emphasis to creativity during play as a social activity and daily practice with meaning within children's (play) interactions. However, we need to understand play as an activity within specific socio-cultural contexts (Vygotsky 1976). According to socio-cultural theory "any human act that gives rise to something new is referred to as a creative act, regardless of whether what is created is a physical object or some mental or emotional construct that lives within the person who created it and is known only to him" (Vygotsky, 2004, p. 7). Play as a context for children's actions, interactions and meaning making processes provides plenty of opportunities for children to be creative. Therefore, it is important to clarify that creativity in this study "is not examined as something separate from the everyday flow of life" (Kantor, Elgas, \& Fernie, 1993, p. 125). This approach is close to what Craft (2002) calls "little c creativity" that accounts for possibility thinking (evident when children face an everyday problem and seek for solutions) and imagination (evident when children produce ideas to solve the problem and find alternatives).

Understanding creativity as an activity that stems from children's intended actions to shape the play context by solving problems, offering solutions, presenting ideas and alternatives for action, one understands that creativity in children's play can not be studied by using standardised tests that measure it. Standardised tests would measure children's behaviour in relation to an already given definition of creativity based on a rational thinking point of view (Clark, 2008 as cited in Saracho, 2012, p. 6). Rather, a need to look at how children may be creative, thus able to create new meanings or constructs in specific contexts can provide new insights about children's creativity. Thus, the theoretical framework of the study highlights that we should search for creativity in play as an interactional and meaningful process, rather as an individual ability. This choice stresses children's agency and ability to be creative versus their passivity to come up and be measured according to adult already decided definitions of creativity. 
Regarding the context of play in early childhood education, classrooms can be viewed as cultures where life is patterned, constructed over time by its members interacting with, and reacting to each other (Kantor, Elgas, \& Fernie 1993). Thus, it is important to look at the peer culture and school culture that contextualises everyday children's free play. Peer culture has been defined as a set of activities, values and shared understandings which are actively co-constructed by children through their daily routines (Berentzen, 1984; Corsaro, 1997; Corsaro \& Eder, 1990). School culture, on the other hand, refers to participants' (both teachers' and children's) practices and interpretations developed in the daily practice of the kindergarten such as rules about the use of space and the daily program, practices for negotiating these rules and teachers' strategies to construct knowledge as well as control children's behavior (Tsigra, 2014).

The new sociology of childhood speaks about children's agency in the world they live in through different processes. James Jenks, and Prout (1998) refer to cultural reproduction and Corsaro (1997) to interpretive reproduction through which children either select and adapt adults' (practitioners') values to their interests, showing flexibility and problem solving capacity or construct new meanings, forms and activities that add to the adult culture, by providing original ideas, imaginative scenaria and alternative solutions. In this way, children's actions/interactions are innovative and creative since they either change the meaning of a given material or situation or offer a new one. The underlying principle in both cultural and interpretive reproduction is that children's actions interact with structural constraints showing the possibility for children's agency and creativity in managing them. Studies highlighting this perspective in the Greek early childhood education context have shown children's abilities to shape the world they live in through material and symbolic transformations of space that are constructed to fulfil children's wishes during play (Germanos, 1993, 2002) and by negotiating roles, rules and actions within the peer and school culture (Tsigra, 2003).

At the same time, early childhood practitioners are responsible for allowing wide or narrow interactional spaces for children's participation in the educational process (Bae, 2009). Practitioners' practices seem to focus on obedience, good manners and traditional thinking as obstacles to children's creativity (Saracho, 2012). Another issue regarding teachers' practices is the fact that they can be unaware and inconsistent with regard to creativity fostering classroom environment issues (Konstantinidou, Gregoriadis, Grammatikopoulos, \& Michalopoulou, 2013).

Overall, creativity is not about pleasing adults. The fact that it is done 'naturally' and within play (rather than teacher-directed learning) contexts and that it stays in the hands of children, is not enough of a reason to skip our interest (May, 2007, p. 99) and loose its significance concerning children's participation in the world they live in. Creativity and play are therefore linked by identifying children's meaningful and intended interactions to change the context of play (time, space, rules, scenaria) through adaptation and or negotiation of adult values and concerns and construction of new meanings, forms and activities that add to existing culture.

This theoretical positioning based on socio-cultural theories and the new sociology of childhood raises important questions about the definition of creativity (is creativity an individual, cognitive capacity or/and a social, co-constructed process?) and the importance of creativity in education (does creativity need to be related to curriculum 
oriented - learning to be important? can everyday creativity be an eminent creativity? Who values which creativity and for what reason?).

The understanding of play in relation to children's creativity is put forward in the current research by asking two main questions:

a) In what ways may children be creative during free-play activities?

b) How can early childhood teachers' values, organization of educational practice and classroom rules intervene in the opportunities and ways children may be creative during play?

\section{Methodology}

My theoretical stance argues for an understanding of the value and practice of play from a socio-cultural perspective. This has specific methodological consequences related to the choice of an ethnographic approach of play in early childhood education settings in the current research. Children's play is studied in the context of peer culture and school culture, as a dynamic and changing process, rather than as a static situation. The aim is to understand the complex and locally constructed realizations of play by practitioners and children in ECE settings. Specifically, the ethnographic interest focuses on understanding the complex and locally constructed cultural knowledge held by the group of peer players (Kantor, Elgas, \& Fernie, 1993) as well as the context of educational practices that practitioners choose during children's play.

Within this framework, methods included ethnographic observations and interviews with children and early childhood practitioners in two early childhood settings in the centre of Thessaloniki for a period of eight months. Both classrooms consisted of twenty 5-6 year old children and both teachers had more than 20 years of teaching experience and similar teacher education ( 2 years Bachelor degree). Observations were made for 90 minutes on a daily basis starting from the opening time (8:10 a.m.) to the end of "free" play activities (9:40 a.m.). Each observed play incident was recorded and studied in relation to specific axis: a) the context of play (who played with whom, where, what and for how long), (b) children's interactions during play (who initiated play, what was the scenario of play and how it developed and/or ended through children's interactions or teachers' interventions) and (c) the teacher's role during children's free play (when and why the teacher intervened/participated in play and for how long, what were the children's response to this participation/intervention). The play incidents observed and specifically the children's actions and interactions within them were analysed by looking at a) how and in what context children constructed collaboratively and creatively their own perspective by utilizing elements of the existing peer and school culture, b) how children constructed ways to adapt, negotiate or resist adult rules and practices that restricted their wishes, interests and priorities (problem-solving situation) and c) how children constructed scenaria and roles producing symbolic representations without relevant material and symbolic transformations of space to fulfill their play choices. Thus the analysis was consistent with the theoretical framework looking for instances that children created new meanings or constructs and how they interacted with specific contexts to shape actively the everyday life in the kindergarten.

Semi-structured interviews with the practitioners aimed to describe their priorities, their views about the value of play as well as children's and teacher's role during 
play. The two classrooms as research settings were different regarding teacher's priorities, roles and rules during play as this will be shown in the results. Last, children were asked to comment on their playmate choices and what pleased them or not during their play. Constant comparative analysis of observed play incidents (Glaser \& Strauss, 1967) provided a set of themes under which data were interpreted and gave answers to the research questions. These themes were use of space, management of time, rules, priorities, teacher-children interactions, peer interactions and negotiation/resistance.

\section{Results}

The research results showed that play and creativity were related in two ways: play performed both as a context and as a motive for children's creativity because it was a basic peer culture concern together with friendship. Children chose someone to be their friend because they played together and at the same time reasoned their friendships due to the fact that they played with the specific children.

Play as a context gave opportunities and reasons for being creative in problem solving situations. These problem solving situations related to children's motivation to satisfy their interests and wishes concerning play such as fitting/adjusting/transforming space and objects with their play scenario or negotiating rules to satisfy their playmates' inclusion or exclusion from play. In addition, play as a social, relational activity required the creation of intersubjective meanings and the co-construction of ways of playing. Thus, it required exchange of information, negotiation and synthesis of ideas and sometimes the emergence of original ideas and meanings. The intersubjectivity and the process of co-construction of meaning during play was evident when children created new spaces for play (original idea) or extended the play area (flexibility). Children also found new ways of playing in a specific area of play (co-constructed new meanings in imaginary situations), ignored rules (how many can play in a specific play area) or negotiated rules (hid in available places to avoid other children's participation in their play) in order to satisfy their playmate choices and friendship interactions (flexibility).

In classroom one, in front of the entrance where there was ample space, a game started which involved 10 out of the 20 children of the class. Children started lifting their chairs from the circle time area and placing them one after another to form a line. They sat on them and pretended that they were passengers on a train. The boy that sat in the front of this line pretended to be the driver of the train and whistled making the sound of the train, while the passengers were all singing a song and producing the sound of the train. Sometimes the driver announced the stops and some passengers took off while others sat on the chairs. This was an innovative way of creating a new space for play after mutual agreement a joint decision to play "the train". Children chose a space that allowed a big group of children to play, formed the train by using chairs as seats, different roles (driver and passengers) and making sounds representing the train. Thus, they organised a new space for play through their active participation and the use of cultural tools to respond to the needs of their desired play scenario.

On one other occasion, the home corner was converted to a castle. Because the knights could not play with their swords in the castle due to lack of space they expanded the play area outside the home corner, thus transforming space symbolically to fit it to their play needs (Germanos, 1993). In addition, children constructed new ways of playing 
in areas which were related to specific scenaria and patterns of play. This for example was the home corner, where usually children played family (mum, dad and children), cooked and looked after their babies. During observations in classroom one, a triad of boys was observed to initiate a new game in the home corner which was repeated many times. They picked clothes from a suitcase close to the home corner that aimed to enhance the children's dressing up and role play. With these clothes they covered all of the home corner, floor, objects etc. very neatly and after covering the whole area they started tidying up the clothes again. Thus they did not only use their imagination to find a new way of playing in a specific area but they co-constructed a new meaning for the use of clothes in the home corner through intersubjective agreement.

The children also ignored rules on several occasions (how many children could play in a specific play area) or negotiated rules, other times openly with the teacher or covertly, depending upon the school culture context, as I will show later. For example, they were hiding available space for children's participation in play when they did not want to accept someone as their playmate in the given setting.

Children often changed the use of objects to fit them to their play scenario. For example, they turned a table upside down to become a boat for the pirates or they turned a construction block to a flying carpet that rescued a soldier from a battle in a castle.

We found that one basic factor affecting the opportunities for play to act as a context for children's creativity was the early childhood teacher's priorities that in turn affected the organization of time and space in the classroom, the rules and expectations from children's behaviour and interactions. As I have mentioned before the two classrooms were not characterized by similar educational processes. In the first classroom the practitioner's priorities emphasized the importance of children's social interactions and freedom of choice during play. The teacher used mainly democratic processes of decision making and allowed ample time for children's free play without being bound to a distribution of time between free and structured children's activities. Thus, she acknowledged the value of children's play interactions in relation to the aims of early childhood education. Children felt free to use the classroom space and construct their play activities in the classroom. When the children asked the teacher's permission to do something, like giving a bath to the doll in the classroom sink, the teacher responded positively to the children's negotiations of space and time. The teacher discussed with the children their fights and disputes and always involved them in their solution. Children developed an inclusive play culture although they had close friendships with their peers. These friendships opened up in terms of size as time went by.

In the second classroom the teacher's priority emphasized children's learning to "work" (responding to teacher directed tasks) and their readiness for primary school. Teacher's emphasis on preparing children to be ready for primary school was evident in the teacher's choice to assign individual tasks during free play time that involved writing skills and colouring "within borders" on provided photocopied material. Improvement of children's verbal expression was also a basic concern for the teacher and thus she perceived teacher-directed activities as very important. Children's appropriate behaviour was discussed a lot among teacher and children and children knew very well the teacher's expectations. Children attempted to overcome the teacher's control and the resist the imposed restrictions in their peer interactions as this will be shown in the following example. Entry in play was very often negotiated even among friends and specific cliques, 
thus exclusive relationships were developed in the class. Overall, children recognised the teacher's expectations and rules but also showed resistance to the school culture by reconstructing elements with new meaning (inclusion or exclusion from play) or negotiating directly with the teacher or silently transcending rules or establishing new meanings in play that were important to them.

One example of such resistance was observed when children started to bring toys from home (usually super hero dolls or new games they had recently acquired) that used them to negotiate participation in play or to attract new friends (i.e. 'I will give you my doll if you are my friend or if you play with me'). However, the use of these toys as "negotiation tools" during their interactions created tensions and conflicts. The teacher asked children to share the toys brought from home with everyone in the class. The children did not follow the teacher's rule because that would mean that the toys would loose their power to function as a means of exchange among friends and at the same time as a motive for non friends to request the friendship of the toys' owners. Later, the teacher prohibited children from bringing toys from home but the children started to bring smaller toys or things from home that could fit in their pockets and hands and use them in the same way as bigger toys. The fact that children recognized the adult values and practices (school culture) and found a flexible and innovative solution to support their wish to bring things from home is an example of children's creativity to solve a problem in context. The problem in the specific case was how to keep bringing things from home that had an "exchange value" within the peer culture without openly confronting the teacher's rules and restrictions.

In addition, the teacher in the second classroom often asked the children to complete a task before choosing where and with whom they would play. Thus, her priority to prepare children for the primary school intervened in terms of time allowed for children to play "freely". Sometimes, children managed this situation by asking their best friends, who were more capable in fulfilling the task, to assist them, when the teacher was not looking, so they could finish the task quickly and move to the play areas together with their best friend. Creativity in this case is understood as finding an alternative solution to a problem that arises when the teacher's and the children's wishes conflict with each other and at the same time the teacher has the power to control access to free play, if a task has not been completed beforehand. The children, in this case, understood both the teacher's priorities (to complete the task) and their peers' priorities (to play) and utilized this knowledge competently to fulfill their wish for play.

In the second classroom, children were not satisfied when the teacher interrupted their play gathering them in circle-time and thus stopping the course of play and they complained that they needed more time to play. In the first classroom, children were pleased because they felt that they had the freedom to move objects or furniture, to form bigger play groups without the limitations set by rules about the number of children allowed to play in each area and because they had ample time for play.

What is important to notice in the previous examples is that, despite the differences in the teachers' practices during free play, the children were able to express their creativity by acting upon their own interests and sometimes resisting the teacher's choices and restrictions. Thus, children found creative ways to manage the obvious power relations in the classroom and be active in shaping the everyday life in their classroom. 


\section{Discussion}

This research showed that play can form a context for children to be creative since they organized collectively their intended actions to fulfill their play wishes and ideas within the peer and school culture. These results are aligned with other research findings that show the children's ability to shape the daily reality of their classroom through construction of new meanings and negotiation of existing culture (Germanos, 1993; Corsaro, 1997; Tsigra, 2003) and underline the "little c creativity" observed in everyday contexts (Craft, 2002).

Results also showed that there are different factors affecting the possibilities for children's creativity during play, such as the organisation of time, space and rules during play. These factors relate closely to early childhood teachers' priorities and appreciation of the value of play as a relational, creative and meaningful activity. Stressing the role of early childhood education in relation to the preparation for primary school, academic success and development of competence seems to lead to the teacher's control of time, space and activities and at the same time it leaves little space for children's self-directed play and its understanding as a socio-cultural activity. This result backs up previous research that highlights the relationship between teachers' priorities and play practices in early childhood education (Loizou \& Avgitidou, 2014).

At the same time, current educational approaches provide an alternative example of how learning can be fostered based on play pedagogies rather teacher-directed pedagogies (Wood, 2004, 2010). In any case, it was important to observe that children responded to a dominant school culture by negotiating openly or resisting the teacher's choices and rules without obvious confrontation.

An appreciation of play relates to an appreciation of childhood experience in the here and now sphere and the recognition of the children's contribution as citizens in the world they live in as their voices are heard and their daily experience and practice are recognised in the shaping of the world. Therefore, linking creativity to play depends on our theoretical as well as political positioning in relation to childhood as a social category and to the aims of early childhood education. This positioning provides the lense through which we can observe, understand and appreciate the children's creativity as a coconstructed everyday social process that relates to the successful satisfaction of the children's interests and purposes within a specific context - rather than only as an individual, psychological characteristic. An approach that describes specific prerequisites and preconditions for creativity may not be enough if we want to foster creativity in the early childhood education classroom. Rather an understanding of the values that underlie the educational practices and how these may be related to opportunities to enhance and realise children's creativity within play may be more appropriate. Such an approach requires special attention to the ways we educate both becoming and in-service early childhood teachers to observe play, rethink their beliefs and practices and have a critical stance upon who makes decisions about the context of play, within which processes and for what reasons. The need for practitioners to share power with children in ECE, be able to observe and recognise the benefits of play, linking it to meaningful learning calls upon a systematic and focused support of ECE to question, research, reflect and replan their actions during children's play has become apparent. 


\section{References}

Avgitidou, S. (2001) (Ed.). Play: Current research and educational approaches (in Greek). Athens: Tipothito-Giorgos Dardanos.

Bae, B. (2009). Children's right to participate-challenges in everyday interactions. European Early Childhood Research Journal, 17(3), 391-406.

Berentzen, S. (1984). Children constructing their social world. Bergen studies in social anthropology. Occasional papers in social anthropology no. 36. Bergen: University of Bergen.

Corsaro, W. (1985). Friendship and peer culture in the early years. Norwood: Ablex.

Corsaro, W. A. (1997). The sociology of childhood. Thousand Oaks: Pine Forge Press.

Corsaro, W. A., \& Eder, D. (1990). Children's peer cultures. Annual Review of Sociology, 16, 197220.

Craft, A. (2002). Creativity and early years education. London: Continuum.

Germanos, D. (1993). Space and educational processes. The educational quality of space (in Greek). Athens: Gutenberg.

Germanos, D. (2002). The walls of knowledge (in Greek). Athens: Gutenberg.

Glaser, B. G., \& Strauss, A. L. (1967). The discovery of grounded theory: strategies for qualitative research. New York: Aldine de Gruyter.

Hännikainen, M., Singer, E., \& van Oers, B. (2013). Promoting play for a better future. European Early Childhood Education Research Journal, 21(2), 165-171.

James, A., Jenks, C., \& Prout, A. (1998). Theorizing childhood. Cambridge: Polity Press.

Kantor, R., Elgas, P. M., \& Fernie, D. E. (1993). Cultural knowledge and social competence within a preschool peer culture group. Early Childhood Research Quarterly, 8, 125-147.

Karila, K. (2012). A nordic perspective on early childhood education and care policy. European Journal of Education, 47, 584-595.

Konstantinidou, E., Gregoriadis, A., Grammatikopoulos, V., \& Michalopoulou, M. (2014). Primary physical education perspective on creativity: the nature of creativity and creativity fostering classroom environment. Early Child Development and Care, 184(5), 766-782.

Loizou, E., \& Avgitidou, S. (2014). The Greek-Cypriot Early Childhood Educational Reform: Introducing play as a participatory learning process and as children's right. Early Child Development \& Care, 184(12), 1884-1901.

May, P. (2007). Play and Creativity. In Nurse, D. A. (Ed.), The new early years professional. Dilemmas \& debates (pp. 95-110). Oxon: Routledge.

Moss, P. (2007). Bringing politics into the nursery: early childhood education as a democratic practice. European Early Childhood Education Research Journal, 15(1), 5-20.

Saracho, O. (2010). Young children's creativity and pretend play. Early Child Development and Care, 172(5), 431-438.

Saracho, O. (2012). Creativity theories and related teachers' beliefs. Early Child Development and Care, 182(1), 35-44.

Tsigra, M. (2003). Friends and pupils in the kindergarten. Formation practices and processes. (Unpublished PhD thesis -in Greek). National and Kapodistrian University of Athens. 
Tsigra, M. (2014). Inside the Kindergarten. Processes and practices of constructing daily reality (in Greek). Athens: Lexitypon.

Vygotsky, L. S. (1976). Play and its role in the mental development of the child. In J. Bruner, A. Jolly, \& K. Sylva (Eds.), Play: Its role in development and evolution (pp. 536-552). New York: Basic Books.

Vygotsky, L. S. (2004). Imagination and creativity in childhood. Journal of Russian and East European Psychology, 42(1), 7-97.

Wood, E. (2004). Developing a pedagogy of play. In A. Anning, J. Cullen, \& M. Fleer (Eds.), Early childhood education. Society and culture (pp. 17-30). London: Sage Publications.

Wood, E. (2010). Reconceptualizing the play-pedagogy relationship: From control to complexity. In L. Brooker \& S. Edwards (Eds.), Engaging Play (pp. 11-24). Berkshire: Open University Press. 